\title{
A retrospective study on molar furcation assessment via clinical detection, intraoral radiography and cone beam computed tomography
}

Wenjian Zhang ${ }^{1 *}$, Keagan Foss ${ }^{2}$ and Bing-Yan Wang ${ }^{3}$

\begin{abstract}
Background: Accurate determination of bone loss at the molar furcation region by clinical detection and intraoral radiograph is challenging in many instances. Cone beam computed tomography (CBCT) is expected to open a new horizon in periodontal assessment. The purpose of this study was to compare and correlate accuracy of molar furcation assessment via clinical detection, intraoral radiography and CBCT images.

Methods: Eighty-three patients with chronic periodontitis who had existing CBCT scans were included. Furcation involvement was assessed on maxillary and mandibular first molars. Periodontal charts (modified Glickman's classification), intraoral (periapical and/or bitewing) radiographs (recorded as presence or absence) and axial CBCT reconstructions were used to evaluate furcation involvement on buccal and palatal/lingual sites. The correlation of furcation assessment by the three methods was evaluated by Pearson analysis.

Results: There were significant correlations $(p<0.05)$ between clinical detection and intraoral radiography, clinical detection and CBCT, as well as intraoral radiography and CBCT at all the measured sites ( $r$ values range between 0.230 to 0.644$)$. CBCT generally exhibited higher correlation with clinical detection relative to intraoral radiography, especially at distal palatal side of maxillary first molar $(p<0.05)$. In addition, $C B C T$ provided more accurate assessment, with bone loss measurement up to 2 decimals in millimeters, whereas clinical detection had 3 classes and the intraoral radiographs usually only detected the presence of furcation involvement in Glickman Class 2 and 3.
\end{abstract}

Conclusions: This study validates that CBCT is a valuable tool in molar furcation assessment in addition to clinical detection and intraoral radiography.

Keywords: Furcation involvement, Clinical detection, Intraoral radiography, CBCT

\section{Background}

Furcation involvement (FI) refers to the condition when periodontal disease has caused bone resorption into the bifurcation or trifurcation of a multi-rooted tooth [1]. Dentists commonly encounter the difficulty of accurately assessing molars with FI, due to limited physical access, morphological variations and measurement errors [2-4]. Any discrepancies between pre-and intra-surgical findings of FI may lead to alterations of surgical treatment

\footnotetext{
*Correspondence: Wenjian.Zhang@uth.tmc.edu

'Department of Diagnostic \& Biomedical Sciences, University of Texas School of Dentistry at Houston, 7500 Cambridge Street, Houston, TX 77054, USA Full list of author information is available at the end of the article
}

plan [5] and unanticipated treatment costs (financially and temporally) [6]. Therefore, management of FI has presented as one of the greatest challenges to the success of periodontal therapy [7].

Traditionally, FI is assessed with a combination of clinical detection and intraoral radiographs [8]. Clinically, FI is evaluated with a Nabers probe, and categorized according to Glickman's or Hamp's classification system based on horizontal bone loss at the furcation area $[9,10]$. However, the accuracy of clinical detection largely depends on operator technique, and many times, the measurement is reflective of penetration depth into the inflamed connective tissue, instead of the actual depth of the inter-radicular

(c) The Author(s). 2018 Open Access This article is distributed under the terms of the Creative Commons Attribution 4.0 International License (http://creativecommons.org/licenses/by/4.0/), which permits unrestricted use, distribution, and reproduction in any medium, provided you give appropriate credit to the original author(s) and the source, provide a link to the Creative Commons license, and indicate if changes were made. The Creative Commons Public Domain Dedication waiver (http://creativecommons.org/publicdomain/zero/1.0/) applies to the data made available in this article, unless otherwise stated. 
bony defect [11]. In addition, factors such as tooth position, inclination, root morphology, length of root trunk, degree of root separation and configuration of residual inter-radicular bone, all affect accuracy of clinical furcation assessment $[12,13]$. Periapical (PA) or bitewing (BW) radiographs are commonly used intraoral projections to supplement clinical detection for furcation assessment $[8,14]$. These $2 \mathrm{D}$ imaging are generally considered to have low sensitivity but high specificity for furcation detection, mainly due to inherent shortcomings of $2 \mathrm{D}$ projections, such as superimposition and angulation problems [15]. Detectability of early FI by intraoral radiographs is especially limited and inconsistent [16].

Cone beam computed tomography $(\mathrm{CBCT})$ is capable of generating accurate and reliable submillimeter-resolution images in all spatial dimensions, with cost and absorbed doses much lower than conventional CT [17, 18]. The applications of $\mathrm{CBCT}$ in dentistry are increasing rapidly, including in periodontology $[19,20]$. CBCT is expected to reveal marginal bone contours as well as infrabony and furcation defects [21], therefore plays a role in the assessment and treatment planning of molars with FI. Currently, there are limited studies comparing diagnostic accuracy of FI by clinical detection, intraoral radiography and CBCT $[12,22,23]$. The aim of the present study was to compare and correlate assessment of molar FI via these three methods, to help further develop evidence on the applicability of CBCT in molar FI assessment.

\section{Methods}

\section{Subjects}

An Institutional Review Board (IRB) approval was granted prior to the start of the study (HSC-DB-17-0370). The patients who visited the University of Texas School of Dentistry at Houston dental clinic from 2012 to 2016 were retrospectively screened according to the selection criteria. The inclusion criteria were: 1) subject was diagnosed as having generalized moderate or severe chronic periodontitis; 2) subject had comprehensive periodontal examination and information had been stored in the school's Electronic Health Record (EHR); 3) subject had diagnostic quality periapical and/or bitewing radiographs covering posterior dentition; 4) subject had diagnostic quality CBCT scan with coverage of entire maxilla and mandible. Majority of the patients had CBCT scans for implant treatment planning purpose, and the time interval between periodontal clinical exam and CBCT scan was less than 3 months. All of the patients who met the inclusion criteria were included in the study, and their first molars of maxilla and mandible bilaterally were assessed according to the following methods.

\section{Intraoral radiographic acquisition}

All the intraoral radiographs were acquired with Focus wall-mounted unit (Instrumentarium Dental, Charlotte,
NC, USA). The unit was operated at 70 peak kilovolt $(\mathrm{kVp}), 7 \mathrm{~mA}(\mathrm{~mA})$, and an exposure time corresponding to the exposed area. All the radiographs were taken with XCP receptor-holding devices (Dentsply Rinn, Elgin, IL, USA) and the paralleling technique. Photostimulable phosphor (PSP) plates (Air Techniques, Melville, NY, USA) were utilized as the receptor, and were scanned with the Scan-X Intraoral scanner (Air Techniques) after exposure. The images were stored in the EHR of the School of Dentistry, displayed on a 19-in. flat panel screen (HP Development Company, Palo Alto, CA, USA) with a 1920 X 1080 pixel resolution, and observed under a dimly lit environment.

\section{CBCT imaging acquisition}

All of the CBCT scans were taken at the Imaging Clinic of University of Texas School of Dentistry at Houston. The included scans covered maxillary and mandibular arches with a field of view (FOV) of $150 \times 90 \mathrm{~mm}^{2}$. The scans were acquired at $90 \mathrm{kVp}, 10 \mathrm{~mA}, 16 \mathrm{~s}$ and a $0.2 \mathrm{~mm}^{3}$ voxel size with a Kodak 9500 unit (Carestream Health, Inc., Rochester, NY, USA). CBCT images were reconstructed with Anatomage Invivo 5 software (Anatomage Inc., San Jose, CA, USA) at $1 \mathrm{~mm}$ thickness. All images were viewed on the same monitor and environment as the intraoral radiographs.

\section{Comprehensive periodontal evaluation Clinical periodontal assessment}

All subjects had comprehensive periodontal examination by the pre-doctoral dental students under the supervision and approval of a periodontal faculty. The evaluation included an assessment of molar furcation involvement according to modified Glickman's classification [10] (Fig. 1). Briefly, this classification was defined as: Class I, incipient or early stage of furcation involvement, bone destruction is less than $2 \mathrm{~mm}$ into the furca; Class II, horizontal bone destruction extending deeper than $2 \mathrm{~mm}$ but less than $6 \mathrm{~mm}$ into the furca; Class III, horizontal bone destructions communicate between furcae of the tooth, and result in a through-and-through tunnel.

\section{Intraoral radiographic assessment}

First molar furcation status was evaluated on molar PA and/or BW radiographs. Presence of triangular radiolucency at the furcation area, and/or alveolar bone level was observed below furcation were radiographic signs for FI. FI was recorded as presence or absence based on the intraoral radiographs (Fig. 2).

\section{CBCT imaging measurements}

First molar furcation assessment was conducted mainly on reconstructed CBCT sagittal and axial views. Presence of FI was demonstrated as loss of trabecular bone 


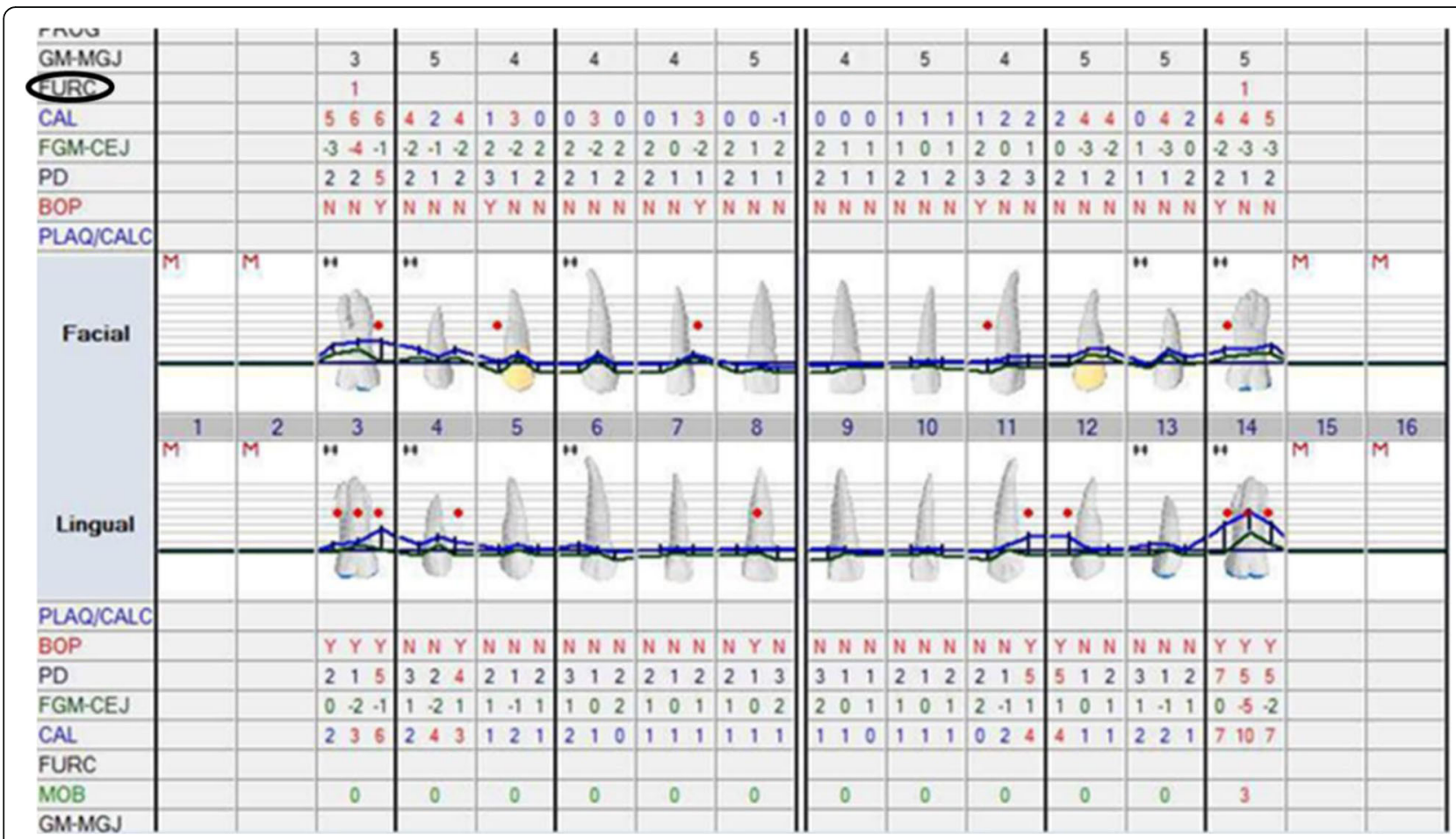

Fig. 1 Periodontal chart demonstrates classification of molar furcation involvement

at the furcation region on both axial and sagittal view. The depth of FI was measured on axial view where the slice showed the greatest amount of bone loss. On this slice, a line was drawn tangentially to the adjacent root surfaces. The distance from this line to the deepest point of bone loss was designated as the amount of furcation bone loss. If applicable, buccal and/or lingual furcation bone loss was measured for mandibular first molar, and buccal, mesial palatal, and distal palatal furcation bone loss were measured for maxillary first molars (Fig. 3).

All the data were analyzed by one of the co-authors KF, who was a first-year dental student and received adequate training on molar furcation assessment via intraoral radiographs and $\mathrm{CBCT}$ scans. The data were reanalyzed in 7 months to evaluate intra-rater reliability and reproducibility.

\section{Statistical analysis}

Spearman's correlation analysis was used to determine the correlations between clinical detection and intraoral radiography, clinical detection and $\mathrm{CBCT}$, as well as intraoral radiography and $\mathrm{CBCT}$ at all the measured sites. The difference in the correlation coefficients was analyzed using Steiger's Z-test. Intra-class correlation coefficient (ICC) was calculated to assess intra-rater reliability and reproducibility. The statistical difference was set at $p<0.05$. The statistical analysis were run with SPSS program (version 24, IBM, Armonk, NY, USA).

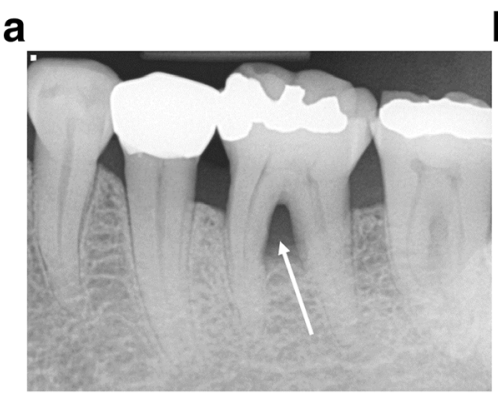

b

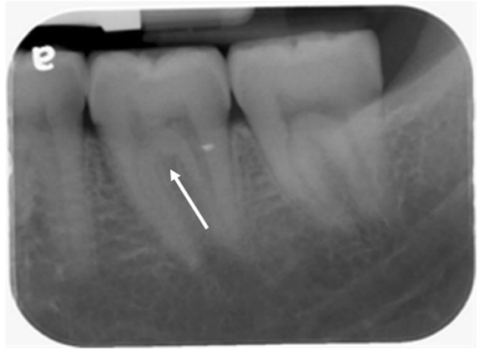

Fig. $\mathbf{2}$ Intraoral radiographs demonstrate molar furcation status. a presence of furcation involvement. $\mathbf{b}$ absence of furcation involvement 
a

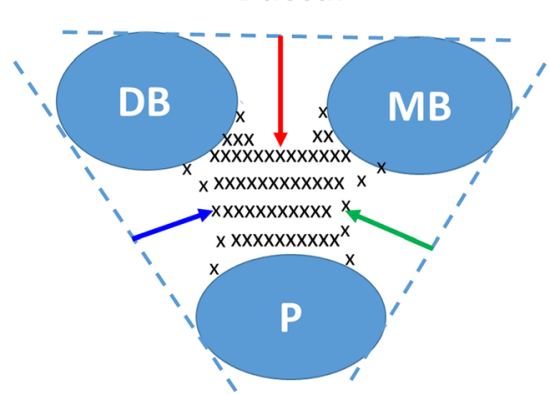

Palatal

C

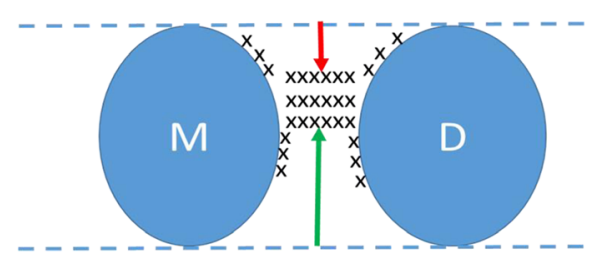

Lingual b

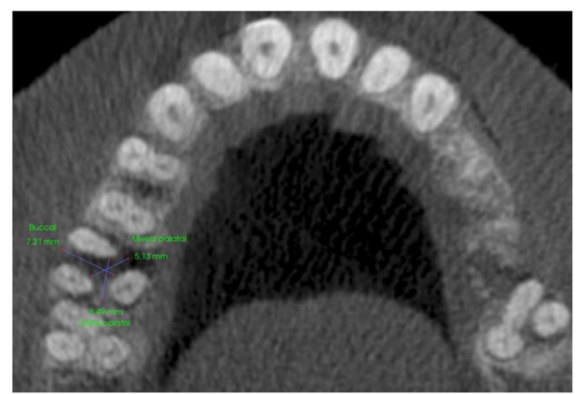

d

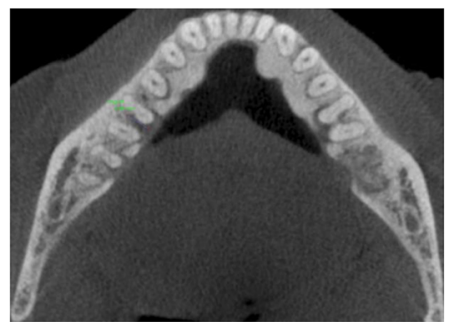

Fig. 3 Measurement of molar furcation involvement on CBCT scans. a a schematic diagram illustrates measurement of furcation bone loss of a maxillary first molar. Dotted line represents tangent line connecting two adjacent root surfaces. Arrows represent distances from the middle of tangent line to the deepest point of bone loss at the different surfaces. Red, green, and blue arrows denote furcation bone loss at buccal, mesial palatal, and distal palatal surface of the molar, respectively. MB, mesial buccal root; $\mathrm{DB}$, distal buccal root; and P, palatal root. $\mathbf{b}$ a representative CBCT axial view demonstrates measurements of furcation bone loss of a maxillary first molar. $\mathbf{c}$ a schematic diagram illustrates measurement of furcation bone loss of a mandibular first molar. Dotted line represents tangent line connecting buccal or lingual surfaces of the two roots, respectively. Arrows represent distances from the middle of tangent line to the deepest point of bone loss at the different surfaces. Red and green arrows denote furcation bone loss at buccal and lingual surface of the molar, respectively. M, mesial root; and D, distal root. $\mathbf{d}$ a representative CBCT axial view demonstrates measurements of furcation bone loss of a mandibular first molar

\section{Results}

Based on a previous study conducted by Qiao et al. [13] who compared molar furcation assessment between clinical probing and $\mathrm{CBCT}$, a power analysis was performed which demonstrated that a sample size of 51 subjects would achieve $80 \%$ power to detect the association between these two evaluation methods on a significance level of 0.05 . To ensure adequate sample size, a total of 83 patients were included in the study. Among these patients, 41 were males, 42 were females, and an age range of 31-86 with a mean age of $59.03 \pm 13.08$ years old.

First molar FI assessed by clinical detection, BW/PA and CBCT were illustrated in Tables 1, 2 and 3, respectively. For maxillary first molar B, MP and DP FI, clinical detection demonstrated a mean modified Glickman's classification of $0.75 \pm 0.08,0.41 \pm 0.08,0.33 \pm 0.07$, respectively, and CBCT assessment revealed a mean 1 . $55 \pm 0.22,0.58 \pm 0.05,0.67 \pm 0.12 \mathrm{~mm}$ bone loss, respectively. For mandibular first molar B and L FI, clinical detection demonstrated a mean modified Glickman's classification of $0.66 \pm 0.10$ and $0.69 \pm 0.09$, respectively, and CBCT assessment revealed a mean $1.52 \pm 0.19$ and $1.15 \pm 0.18 \mathrm{~mm}$ bone
Table 1 First molar furcation involvement assessed by periodontal probing

\begin{tabular}{|c|c|c|c|c|c|c|c|}
\hline \multirow{2}{*}{$\begin{array}{l}\text { Modified } \\
\text { Glickman } \\
\text { classificationa }\end{array}$} & \multicolumn{4}{|c|}{ Maxillary first molar } & \multicolumn{3}{|c|}{ Mandibular first molar } \\
\hline & $B$ & MP & $\mathrm{DP}$ & Average & $B$ & $\mathrm{~L}$ & Average \\
\hline Not present ${ }^{\mathrm{b}}$ & $49.1 \%$ & $78.4 \%$ & $83.6 \%$ & $70.4 \%$ & $60.8 \%$ & $53.9 \%$ & $57.4 \%$ \\
\hline Class I & $34.5 \%$ & $7.8 \%$ & $5.2 \%$ & $15.8 \%$ & $18.6 \%$ & $27.5 \%$ & $23.1 \%$ \\
\hline Class II & $9.5 \%$ & $6.9 \%$ & $6.0 \%$ & $7.5 \%$ & $13.7 \%$ & $11.8 \%$ & $12.8 \%$ \\
\hline Class III & $6.9 \%$ & $6.9 \%$ & $5.2 \%$ & $6.3 \%$ & $6.9 \%$ & $5.9 \%$ & $6.4 \%$ \\
\hline Total & $100 \%$ & $100 \%$ & $100 \%$ & $100 \%$ & $100 \%$ & $100 \%$ & $100 \%$ \\
\hline
\end{tabular}

Data are presented as percentage of assayed surfaces without or with furcation involvement of corresponding category based on periodontal charting Abbreviations: $B$ buccal, MP mesial palatal, DP distal palatal, $L$ lingual ${ }^{a}$ Modified Glickman classification: Class I, incipient or early stage of furcation involvement, bone destruction is less than $2 \mathrm{~mm}$ into the furca; Class II, horizontal bone destruction extending deeper than $2 \mathrm{~mm}$ but less than $6 \mathrm{~mm}$ into the furca; Class III, horizontal bone destructions communicate between furcae of the tooth, and result in a through-and-through tunnel

${ }^{\mathrm{b}}$ Not present: no furcation involvement 
Table 2 First molar furcation involvement assessed by periapical or bitewing radiographs

\begin{tabular}{lll}
\hline Radiographic assessment & $\begin{array}{l}\text { Maxillary } \\
\text { first molar }\end{array}$ & $\begin{array}{l}\text { Mandibular } \\
\text { first molar }\end{array}$ \\
\hline Absence of furcation involvement & $71.8 \%$ & $66.0 \%$ \\
Presence of furcation involvement & $28.2 \%$ & $34 \%$ \\
Total & $100 \%$ & $100 \%$ \\
\hline
\end{tabular}

Data are presented as percentage of assayed first molars without or with

furcation involvement based on radiographic assessment

loss, respectively (data were presented as mean $\pm \mathrm{SD}$ ). All of the three evaluation methods demonstrated more frequent FI of mandibular first molars relative to maxillary counterpart. Of maxillary first molars, both clinical detection and CBCT revealed that buccal surface was more vulnerable for FI compared to palatal side.

Comparison of first molar FI assessment between $\mathrm{CBCT}$ and clinical detection showed that, when CBCT demonstrated no furcation involvement, $18.7 \%$ of these cases were documented as FI on clinical detection. On the contrary, of the $26.7 \%$ cases identified as having $0.1-$ $2.0 \mathrm{~mm}$ or $2.1-6.0 \mathrm{~mm}$ bone loss on CBCT, clinical detection showed no FI (Table 4). For comparison between intraoral radiographic evaluation and clinical detection, there were situations when no FI was detected on intraoral radiographs, $25.6 \%$ of these cases were demonstrated to have Class I-III FI by clinical detection. In addition, for $18.2 \%$ cases identified as FI on radiographs, clinical detection failed to detect any bone loss (Table 5).

Spearman's correlation and Steiger's Z-test analysis demonstrated that clinical detection, $\mathrm{BW} / \mathrm{PA}$ and $\mathrm{CBCT}$ were significantly correlated with each other in the assessment of first molar FI, with $r$ values ranged between 0.230 to $0.644(P<0.05$, Table 6$)$. Compared with $\mathrm{BW} /$ PA, CBCT appeared to have higher correlation coefficients with clinical detection, especially at distal palatal side of maxillary first molar, which reached statistically significant difference $(p<0.05$, Table 6$)$. Between the two sets of measurements by the same rater, the ICC was 0 . 903 , with $95 \%$ confidence interval of $(0.858,0.934)$,

Table 3 First molar furcation involvement measured by CBCT

\begin{tabular}{|c|c|c|c|c|c|c|c|}
\hline \multirow{2}{*}{$\begin{array}{l}\text { Depth of } \\
\text { furcation } \\
\text { involvement } \\
(\mathrm{mm})\end{array}$} & \multicolumn{4}{|c|}{ Maxillary first molar } & \multicolumn{3}{|c|}{ Mandibular first molar } \\
\hline & B & MP & $\mathrm{DP}$ & Average & B & L & Average \\
\hline 0.0 & $46.7 \%$ & $81.5 \%$ & $73.9 \%$ & 67.4 & $45.9 \%$ & $54.1 \%$ & $50.0 \%$ \\
\hline $1-2.0$ & $21.7 \%$ & $5.4 \%$ & $16.3 \%$ & 14.5 & $15.3 \%$ & $25.9 \%$ & $20.6 \%$ \\
\hline $1-6.0$ & $25.0 \%$ & $13.0 \%$ & $6.5 \%$ & 14.8 & $36.5 \%$ & $17.6 \%$ & $27.1 \%$ \\
\hline$>6.0$ & $6.5 \%$ & $0.0 \%$ & $3.3 \%$ & 3.3 & $2.4 \%$ & $2.4 \%$ & $2.4 \%$ \\
\hline tal & $100 \%$ & $100 \%$ & $100 \%$ & $100 \%$ & $100 \%$ & $100 \%$ & $100 \%$ \\
\hline
\end{tabular}

Data are presented as percentage of assayed surfaces without or with furcation involvement of corresponding category based on CBCT assessment Abbreviations: $B$ buccal, MP mesial palatal, DP distal palatal, $L$ lingual
Table 4 Cross tabulation of CBCT with periodontal probing for evaluation of furcation involvement for maxillary and mandibular first molars

\begin{tabular}{|c|c|c|c|c|c|c|}
\hline \multirow[t]{2}{*}{ Count } & & \multicolumn{4}{|c|}{ Periodontal probing } & \multirow[t]{2}{*}{ Total } \\
\hline & & 0 & 1 & 2 & 3 & \\
\hline \multirow[t]{4}{*}{$\mathrm{CBCT}(\mathrm{mm})$} & 0.0 & 213 & 36 & 10 & 3 & 262 \\
\hline & $0.1-2.0$ & 40 & 24 & 7 & 0 & 71 \\
\hline & $2.1-6.0$ & 38 & 22 & 13 & 6 & 79 \\
\hline & $>6.0$ & 1 & 2 & 3 & 5 & 11 \\
\hline Total & & 292 & 84 & 33 & 14 & 423 \\
\hline
\end{tabular}

which demonstrated great reliability and repeatability of the evaluator.

\section{Discussion}

Our results demonstrated that all three FI assessment methods had significant correlations among each other. CBCT had stronger correlation to clinical detection than $\mathrm{PA} / \mathrm{BW}$, especially on distal palatal side of maxillary first molar. The results validate applicability of CBCT in FI assessment. Although all of the included patients had diagnosis of generalized moderate or severe chronic periodontitis, more than a half of them were not found to have FI based on the three evaluation methods.

When CBCT showed no furcation involvement, clinical detection identified $18.7 \%$ of cases with FI, indicating over-detection by clinical measurement. On the contrary, of the $26.7 \%$ cases demonstrated bone loss on $\mathrm{CBCT}$, clinical detection showed no FI, suggesting underdetection by clinical detection. This was consistent with what was reported by Darby [12] and Walter [23], who also found over- and under-estimation of FI by clinical probing relative to $\mathrm{CBCT}$ analysis. It is speculated that probing angulation and force, soft tissue inflammation, and inter-radicular bone and root morphology, all contribute to variations of clinical detection.

Between intraoral radiographic examination and clinical detection, there were situations when no FI was identified on intraoral radiographs, about one quarter of these cases were demonstrated having FI by clinical detection. In addition, for $18.2 \%$ cases identified as FI on radiographs, probing failed to detect any bone loss. This observation confirmed the necessity of supplementing

Table 5 Cross tabulation of intraoral radiograph with periodontal probing for evaluation of furcation involvement for maxillary and mandibular first molars

\begin{tabular}{lllllll}
\hline Count & & \multicolumn{4}{c}{ Periodontal probing } & Total \\
\cline { 3 - 6 } & & 0 & 1 & 2 & 3 & \\
\hline Intraoral radiograph & 0 (absence) & 258 & 75 & 13 & 2 & 352 \\
& 1 (presence) & 58 & 17 & 39 & 28 & 142 \\
Total & & 316 & 92 & 52 & 34 & 494 \\
\hline
\end{tabular}


Table 6 Correlation coefficients of periodontal probing with CBCT or BW/PA in assessment of furcation involvement for maxillary and mandibular first molars

\begin{tabular}{lll}
\hline Periodontal charting (Modified Glickman) & CBCT & BW/PA \\
\hline Maxillary buccal & $0.599^{\mathrm{a}}$ & $0.579^{\mathrm{a}}$ \\
Maxillary mesial palatal & $0.591^{\mathrm{a}}$ & $0.499^{\mathrm{a}}$ \\
Maxillary distal palatal & $0.644^{\mathrm{a}, \mathrm{c}}$ & $0.424^{\mathrm{a}, \mathrm{c}}$ \\
Mandibular buccal & $0.372^{\mathrm{a}}$ & $0.362^{\mathrm{a}}$ \\
Mandibular lingual & $0.264^{\mathrm{b}}$ & $0.230^{\mathrm{b}}$ \\
\hline
\end{tabular}

Abbreviations: $C B C T$ cone beam computed tomography, BW/PA bitewing/periapical radiographs

${ }^{a}$ Correlation is significant at $p<0.01$, between CBCT and periodontal charting or between BW/PA and periodontal charting

${ }^{b}$ Correlation is significant at $p<0.05$, between CBCT and periodontal charting, or between BW/PA and periodontal charting

${ }^{\mathrm{C}} \mathrm{CBCT}$ demonstrated significantly stronger correlation $(p<0.05)$ with periodontal charting relative to BW/PA at assessment of distal palatal side of maxillary first molars

clinical detection with intraoral radiographs for the diagnosis of FI, which is reflective of the consensus in the literature $[8,14]$. The inconsistency between these two methods could be due to measurement errors from either or both detecting techniques. Anatomic complexity, such as superimposition of palatal root at the furcation region may contribute to under-diagnosis of FI for maxillary molars on intraoral radiographs [5, 24], and sinus tract extending into furcation due to intrapulpal infection may lead to overdiagnosis of FI on intraoral radiographs [25], respectively.

The current study identified that mandibular first molars had more FI than maxillary first molars. In a study conducted in a Swede population, Svärdström [26] found that the prevalence of furcation involved molars was higher in the maxilla than in the mandible, based on clinical detection and intraoral radiographs. Hou et al. [27] concluded that the highest prevalence of FI was in the mandibular first molar in a Japanese population based on clinical detection. It appears that geographical locations, racial origins and evaluation modalities are among the factors contributing to variations of prevalence for molars with FI. Current study also found that FI was more frequently associated with and more severe at buccal side of maxillary first molars relative to palatal side, similarly as reported by Porciuncula [28].

Although considered a valuable addition in molar furcation assessment, $\mathrm{CBCT}$ is not without its shortcomings. Scatter, partial volume averaging and beam hardening artifacts could compromise its diagnostic quality, especially for patients with heavy metallic restorations, multiple endodontic treatment, orthodontic appliances, or implant prosthesis [29-31]. In addition, detectability of FI by CBCT depends on how sensitive it is to reveal bone loss at furcation area. Generally, demineralization may not be evident radiographically until it reaches approximately 30-40\% [32]. This makes it challenge to detect and initiate early intervention for incipient FI of molars. In general, periodontal probing and intraoral radiographs should be used as routine examinations for detection of FI. For complicated cases when routine exams fail to provide adequate information for diagnosis and/or treatment planning, CBCT may be attempted with the smallest field of view possible and optimal exposure settings.

There were limitations for the study. It was a retrospective investigation, and the clinical detection was performed by different dental students under the supervision of board-certified periodontist, and the results were confirmed by the supervising faculty before being entering in the EHR. Still, inter-operator variations could contribute to inconsistence in the clinical detection. Also, in the present study, a relative old model of CBCT unit, Kodak 9500 was used, since this was the only CBCT unit in the Imaging Clinic of the school. This unit had a smallest voxel size of $200 \mu \mathrm{m}$. Compared to newer CBCT units with much smaller voxel size, such as $80 \mu \mathrm{m}$ for Accuitomo [33], the much larger voxel size of current unit had limited spatial resolution, therefore, could limit the accuracy in the assessment of FI. In addition, current study only measured horizontal bone loss at the furcation area on CBCT scan, in order to correlate with clinical detection. Modified Glickman Classification was utilized in clinical detection, which only recorded horizontal furcation involvement of the molars. Future study could consider incorporating vertical bone loss measurement on $\mathrm{CBCT}$, to gain better appreciation on furcation status. Intra-surgical FI assessment (gold standard) could be implemented, if possible, to further evaluate the accuracy of $\mathrm{CBCT}$ in the diagnosis of FI.

\section{Conclusions}

CBCT has been validated as a valuable supplemental tool for assessment of molar FI in addition to periodontal probing and intraoral radiographic examinations.

\section{Abbreviations}

BW: Bitewing; CBCT: Cone beam computed tomography; EHR: Electronic Health Record; FI: Furcation involvement; FOV: Field of view; IRB: Institutional Review Board; kVp: Kilovolt; mA: Milliampere; PA: Periapical;

PSP: Photostimulable phosphor

\section{Funding}

This study was partially supported by the Research Office, University of Texas School of Dentistry at Houston.

\section{Availability of data and materials}

The datasets generated and/or analysed during the current study are not publicly available, in order to protect participant anonymity. However, these data are available from the corresponding author on reasonable request.

\section{Authors' contributions}

WZ conceived the ideas, designed the experiments, and composed the manuscript. KF did all the measurements and performed initial data analysis. BW refined the ideas, performed in-depth data analysis and interpretations, and critically revised the manuscript. All authors read and approved the final manuscript. 


\section{Ethics approval and consent to participate}

This study was approved by the Institutional Review Board (IRB) of University of Texas Health Science Center at Houston (HSC-DB-17-0370). The need for consent was waived by the IRB, since the study was a retrospective chart review type of study.

\section{Competing interests}

The authors declare that they have no competing interests.

\section{Publisher's Note}

Springer Nature remains neutral with regard to jurisdictional claims in published maps and institutional affiliations.

\section{Author details}

${ }^{1}$ Department of Diagnostic \& Biomedical Sciences, University of Texas School of Dentistry at Houston, 7500 Cambridge Street, Houston, TX 77054, USA. ${ }^{2}$ University of Texas School of Dentistry at Houston, 7500 Cambridge Street, Houston, TX 77054, USA. ${ }^{3}$ Department of Periodontics \& Dental Hygiene, University of Texas School of Dentistry at Houston, 7500 Cambridge Street, Houston, TX 77054, USA

Received: 4 January 2018 Accepted: 27 April 2018

Published online: 03 May 2018

\section{References}

1. Cate T. Glossary of terms. J Periodontol. 1977;48(9):611-2.

2. Al-Shammari KF, Kazor CE, Wang HL. Molar root anatomy and management of furcation defects. J Clin Periodontol. 2001;28(8):730-40.

3. Hempton $\mathrm{T}$, Leone $\mathrm{C}$. A review of root resective therapy as a treatment option for maxillary molars. J Am Dent Assoc. 1997;128(4):449-55.

4. Muller HP, Eger T. Furcation diagnosis. J Clin Periodontol. 1999;26(8):485-98.

5. Walter C, Weiger R, Zitzmann NU. Periodontal surgery in furcation-involved maxillary molars revisited-an introduction of guidelines for comprehensive treatment. Clin Oral Investig. 2011;15(1):9-20.

6. Walter C, Weiger R, Dietrich T, Lang NP, Zitzmann NU. Does three-dimensional imaging offer a financial benefit for treating maxillary molars with furcation involvement? A pilot clinical case series. Clin Oral Implants Res. 2012;23(3):351-8.

7. Ramfjord SP, Caffesse RG, Morrison EC, Hill RW, Kerry GJ, Appleberry EA, Nissle RR, Stults DL. Four modalities of periodontal treatment compared over five years. J Periodontal Res. 1987;22(3):222-3.

8. Mol A. Imaging methods in periodontology. Periodontol. 2004;34:34-48.

9. Hamp SE, Nyman S, Lindhe J. Periodontal treatment of multirooted teeth. Results after 5 years. J Clin Periodontol. 1975;2(3):126-35.

10. Knowles JW, Burgett FG, Nissle RR, Shick RA, Morrison EC, Ramfjord SP. Results of periodontal treatment related to pocket depth and attachment level. Eight years. J Periodontol. 1979;50(5):225-33.

11. Moriarty JD, Hutchens LH Jr, Scheitler LE. Histological evaluation of periodontal probe penetration in untreated facial molar furcations. J Clin Periodontol. 1989:16(1):21-6.

12. Darby I, Sanelli M, Shan S, Silver J, Singh A, Soedjono M, Ngo L. Comparison of clinical and cone beam computed tomography measurements to diagnose furcation involvement. Int J Dent Hyg. 2015;13(4):241-5.

13. Qiao J, Wang S, Duan J, Zhang Y, Qiu Y, Sun C, Liu D. The accuracy of cone-beam computed tomography in assessing maxillary molar furcation involvement. J Clin Periodontol. 2014;41(3):269-74.

14. Laky M, Majdalani S, Kapferer I, Frantal S, Gahleitner A, Moritz A, Ulm C. Periodontal probing of dental furcations compared with diagnosis by lowdose computed tomography: a case series. J Periodontol. 2013;84(12):1740-6.

15. Vandenberghe $B$, Jacobs $R$, Yang J. Detection of periodontal bone loss using digital intraoral and cone beam computed tomography images: an in vitro assessment of bony and/or infrabony defects. Dentomaxillofac Radiol. 2008:37(5):252-60.

16. Hishikawa T, Izumi M, Naitoh M, Furukawa M, Yoshinari N, Kawase $\mathrm{H}_{\text {, }}$ Matsuoka M, Noguchi T, Ariji E. The effect of horizontal X-ray beam angulation on the detection of furcation defects of mandibular first molars in intraoral radiography. Dentomaxillofac Radiol. 2010;39(2):85-90.

17. Ito K, Gomi Y, Sato S, Arai Y, Shinoda K. Clinical application of a new compact CT system to assess 3-D images for the preoperative treatment planning of implants in the posterior mandible a case report. Clin Oral Implants Res. 2001;12(5):539-42.
18. Aljehani YA. Diagnostic applications of cone-beam CT for periodontal diseases. Int J Dentistry. 2014;2014:865079.

19. Acar B, Kamburoglu K. Use of cone beam computed tomography in periodontology. World J Radiol. 2014:6(5):139-47.

20. Mozzo P, Procacci C, Tacconi A, Martini PT, Andreis IA. A new volumetric CT machine for dental imaging based on the cone-beam technique: preliminary results. Eur Radiol. 1998;8(9):1558-64.

21. du Bois AH, Kardachi B, Bartold PM. Is there a role for the use of volumetric cone beam computed tomography in periodontics? Aust Dent J. 2012; 57(Suppl 1):103-8.

22. Cimbaljevic MM, Spin-Neto RR, Miletic VJ, Jankovic SM, Aleksic ZM, NikolicJakoba NS. Clinical and CBCT-based diagnosis of furcation involvement in patients with severe periodontitis. Quintessence Int. 2015;46(10):863-70.

23. Walter C, Kaner D, Berndt DC, Weiger R, Zitzmann NU. Three-dimensional imaging as a pre-operative tool in decision making for furcation surgery. J Clin Periodontol. 2009;36(3):250-7.

24. Bragger U. Radiographic parameters: biological significance and clinical use. Periodontol. 2005;39:73-90.

25. Rotstein I, Simon JH. Diagnosis, prognosis and decision-making in the treatment of combined periodontal-endodontic lesions. Periodontol. 2004;34:165-203.

26. Svardstrom G, Wennstrom JL. Prevalence of furcation involvements in patients referred for periodontal treatment. J Clin Periodontol. 1996:23(12):1093-9.

27. Hou GL, Lin IC, Tsai CC, Shieh TY. The study of molar furcation involvements in adult periodontitis. II. Age, sex, location and prevalence. Kaohsiung J Med Sci. 1996;12(9):514-21.

28. Porciuncula HF, da Porciuncula MM, Zuza EP, de Toledo BE. Biometric analysis of the maxillary permanent molar teeth and its relation to furcation involvement. Braz Oral Res. 2004;18(3):187-91.

29. Draenert FG, Coppenrath E, Herzog P, Muller S, Mueller-Lisse UG. Beam hardening artefacts occur in dental implant scans with the NewTom cone beam CT but not with the dental 4-row multidetector $\mathrm{CT}$. Dentomaxillofac Radiol. 2007;36(4):198-203.

30. Schulze R, Heil U, Gross D, Bruellmann DD, Dranischnikow E, Schwanecke U, Schoemer E. Artefacts in CBCT: a review. Dentomaxillofac Radiol. 2011;40(5):265-73.

31. Brito-Junior M, Santos LA, Faria-e-Silva AL, Pereira RD, Sousa-Neto MD. Ex vivo evaluation of artifacts mimicking fracture lines on cone-beam computed tomography produced by different root canal sealers. Int Endod J. 2014:47(1):26-31.

32. White SC, Pharoah MJ. Oral radiology principle and interpretation. 7th ed. St. Louis: Elsevier Inc.; 2014

33. Pauwels R, Faruangsaeng T, Charoenkarn T, Ngonphloy N, Panmekiate S. Effect of exposure parameters and voxel size on bone structure analysis in CBCT. Dentomaxillofac Radiol. 2015;44(8):20150078.

Ready to submit your research? Choose BMC and benefit from

- fast, convenient online submission

- thorough peer review by experienced researchers in your field

- rapid publication on acceptance

- support for research data, including large and complex data types

- gold Open Access which fosters wider collaboration and increased citations

- maximum visibility for your research: over $100 \mathrm{M}$ website views per year

At BMC, research is always in progress.

Learn more biomedcentral.com/submissions 